\title{
Antibiotic-Producing Bacteria as a Possible Defence of Birds against Pathogenic Microorganisms
}

\author{
Juan José Soler*1,3, Manuel Martín-Vivaldi ${ }^{2,3}$, Juan Manuel Peralta-Sánchez ${ }^{1,3}$ and \\ Magdalena Ruiz-Rodríguez ${ }^{2,3}$
}

\author{
${ }^{1}$ Dpto. Ecología Funcional y Evolutiva. Estación Experimental de Zonas Áridas (CSIC). 04001 Almería, Spain; ${ }^{2}$ Dpto. \\ Biología Animal. Facultad de Ciencias. Universidad de Granada. 18071 Granada, Spain; ${ }^{3}$ Grupo Coevolución, Unidad \\ Asociada al CSIC, Granada, Spain
}

\begin{abstract}
Theory strongly suggests that beneficial symbiotic bacteria could be common within birds. Our argument is based on the existence of within-host competition for resources between bacteria (i.e. bacterial interference), and on the differential effect that host fitness (i.e., reproductive success and probability of survival) has on fitness of different bacteria. If reproductive success of hosts is positively related to that of a first bacterium, and negatively related to that of a second bacterium, it would be of selective advantage for the former to develop chemicals that prevent host infection by the later pathogenic bacterium. Furthermore, we exemplify the possibility that hosts use antibiotic producing bacteria to prevent infections in different body parts (i.e., replacement therapy) or environment (i.e. nest sanitation). We review the up to now few available results suggesting associations of birds with antibiotic producing bacteria that result in fitness advantages to hosts. Evidence for such beneficial associations, however, has been very scarce so far, and an important research effort testing predictions of that relationship in different contexts is needed for a generalization of the hypothesis.
\end{abstract}

Keywords: Egg incubation, embryo infection, mutualism, nest sanitation, nest lining material, symbiosis, uropygial gland.

Bacteria are ubiquitous microorganisms that frequently live in association with other microbes but also with macroorganisms. Symbiosis varies in the mechanisms for achieving and maintaining the associations and, apart of pathogenic effects (parasitic relationship), they can also result in clear benefits for hosts (see [1] for a general view of the role of symbiotic microorganisms in nature). Symbionts, for instance, often enhance host ability to acquire nutrients from the environment or provide the pathways for synthesis of needed organic compounds or for catabolism of molecules available in the environment. Furthermore, because of the capacity of bacteria to synthesize a great variety of bioactive compounds, they usually provide hosts with defensive chemicals that ward off predators, parasites and pathogenic microorganisms. Below, we review the background knowledge explaining the generalized production of chemicals by bacteria and why some bacteria should protect hosts against pathogenic microorganisms. In addition, we also develop arguments suggesting a generalized used of antibiotic producing bacteria by hosts. Finally, we review the avian literature related to symbiotic associations with bacteria, highlighting the possibility that antibiotic producing symbionts may play a role in avian evolutionary ecology.

*Address correspondence to this author at the Dpto. Ecología Funcional y Evolutiva. Estación Experimental de Zonas Áridas (CSIC). 04001 Almería, Spain; E-mail: jsoler@eeza.csic.es

\section{BACKGROUND FOR A GENERALIZED USE OF AN- TIBIOTIC PRODUCING BACTERIA BY MACRO- ORGANISMS IN NATURE}

\section{Chemicals: A Widespread Armament of Bacteria}

Competition for resources and space among bacteria (i.e, interference property [2]) is a common phenomenon driven by chemical battles. Once a bacterium is established, it modifies the chemical environment and creates a physicochemical barrier that impedes the establishment of other bacteria, unless the latter produce counteracting chemicals. Bacteria possess an extraordinary array of microbial defense systems that include classical antibiotics, metabolic byproducts, lytic agents, numerous types of protein exotoxins, and bacteriocines, varying in their antimicrobial capacity from specific actions to broad spectra [3]. When bacteria live in symbiotic relationships with hosting organisms, they use those chemicals in the competition for space or resources with other microorganism including host pathogens. Thus, hosts would benefit from the establishment of relationships with non-pathogenic bacteria acting as barriers preventing colonization of host tissues by pathogenic micro-organisms. Barrier-benefits from symbiotic bacteria against pathogenic micro-organisms have mainly been studied for gut bacteria living in vertebrates [4], but also in insects [5], which indicates that barrier benefits for hosts are likely widespread in nature. Symbiotic bacteria might also produce toxins such as polyketides that confer protection against predators $[6,7]$. Consequently, chemicals from non-pathogenic-established symbionts could provide hosts with protection against 
pathogenic microorganisms and, in some cases, even against predators.

\section{When Should Symbiotic Microorganisms Protect Hosts?}

Protection of the hosts from pathogens would be of selective advantage for symbiotic microorganisms that depend on host survival and/or reproduction for a successful transmission to other hosts [8] and, therefore, the mode of symbiont transmission among hosts would be important when predicting mutualistic relationships between hosts and microorganisms. Most bacteria are able to produce antibiotic substances against other microorganisms [e.g., 9] and, consequently, symbiotic relationships in which the hosts obtain immune benefits would theoretically be common when successful microorganism transmission is closely related to host fitness.

In vertically transmitted symbionts, the effectiveness of transmission to new hosts (from parent to offspring) is closely related to reproductive success of hosts, and therefore they rarely produce negative effects on host survival [1]. Horizontally transmitted parasites, however, do not need successful host reproduction for effective transmission to another host and, consequently, are commonly more virulent for hosts than those vertically transmitted [10]. Vertically and horizontally transmitted symbionts commonly occur within the same hosts, and a conflict of interests over host fitness appears among these two kinds of microbes. In that context, it has been suggested that the conflict between horizontally and vertically transmitted symbionts selects the latter to provide their host with resistance against the former (pathogen and parasites) microorganism [11]. Furthermore, this scenario also explains why mutualistic relationships between macro- and microorganisms are more commonly established with vertically transmitted parasites [1].

Vertical transmission however is not a requisite for the establishment of mutualistic relationships between microand macroorganisms [12] and, if healthy hosts provide environments that enhance the fitness (i.e. transmission) of some symbionts, but not that of others, a conflict between these two kinds of microorganisms over the health of the host would also occur. Again, this conflict would select for hostfavored symbionts providing their hosts with resistance against pathogens, parasites, or even predators (see examples in [11]). Therefore, the differential association between host fitness and reproductive success of different coexisting symbiotic microorganisms is the key assumption for predicting the evolution of mutualistic relationships between hosts and microorganisms. This relationship would therefore provide hosts with symbiont-mediated-protection against other symbionts: those that negatively affect fitness of both hosts and mutualistic microorganisms.

Symbiont-mediated-protection has mainly been studied in invertebrate hosts $[1,11,13,14]$, but recent studies also provide evidence for its existence in vertebrates, including amphibians [15], birds [16], and mammals [17]. Therefore, this kind of mutualistic relationships are likely widespread in nature [12].

\section{Could Host Use Antibiotic Producing Bacteria?}

Once a host body location harbours beneficial bacteria, they could even be moved to a different body part. In the case of a pathogenic infection, and appropriate environ- mental conditions, beneficial bacteria may thus replace pathogenic ones and, consequently, cure or prevent infections. In human medicine, bacteria translocation has been used as a medical therapy (replacement therapy) and consists on the implantation of effecter bacteria in body parts at high risk of infection [18]. The effectiveness of colonization with benign bacteria to prevent or eliminate pathogenic ones has been tested, for instance, in the prevention of dental caries, otitis media, and streptococcal pharyngitis. Although these therapies are not commonly used yet, the future appears to hold great promise for its use to prevent and control bacterial infections in humans [18]. Due to the likely great benefits associated with the translocation of beneficial bacteria between body parts, animals might also practice replacement therapies with beneficial bacteria. This possibility, however, has rarely been investigated.

Translocation of beneficial bacteria from one to other places for preventing infection has been detected in nature. One of these examples is related to fungus-growing ants that use symbiotic bacteria living in their metapleural gland to inhibit growth of pathogenic fungi not on their body but on their crops [19]. Antibiotic producing bacteria living on the skin of salamanders [15], or in the uropygial gland of hoopoes (Upupa epops) [16], that are moved to eggs to protect embryos against infections, may also be and example of "replacement therapy" in nature. Sanitation with saliva by insects and mammals might also imply the translocation of antibiotic producing bacteria that prevent infections [20,21].

Summarising, there are good theoretical reasons for hypothesizing that antibiotic producing bacteria living in animal hosts are widespread in nature, and that the protection of hosts against pathogenic microorganisms would be of selective advantage for some mutualistic but not for other symbiotic bacteria. Because of the direct benefits for hosts harbouring such protective bacteria, it could also be hypothesised that host traits favouring growth and use of the beneficial microorganisms should have been selected throughout the evolutionary history of animals. Below, we review some evidence of symbiotic associations between antibiotic producing bacteria and birds. Because of the scarcity of studies in birds, we also speculate and hypothesise possible scenarios where such relationship is possible.

\section{BIRDS AND ANTIBIOTIC PRODUCING BACTERIA: EVIDENCE OF MUTUALISTIC RELATIONSHIPS}

\section{Antibiotic Producing Bacteria Within the Gastrointesti- nal Microbiota}

It is well known that the intestinal microflora has profound effects, not only on the anatomical and physiological development of hosts, but also on their immune system [22]. Autochthonous microflora stimulate the host immune system to respond more quickly to pathogen challenges and, through bacterial interference, inhibit colonization of the gastrointestinal tract by overt exogenous pathogens [4]. Therefore, it is likely that antibiotic producing bacteria play an important role in maintaining the optimal bacterial community for food digestion in the intestinal tract of the bird host. In accordance with a positive effect of antibiotic substances in the gastrointestinal tract, it has experimentally been shown that feeding with antibiotics enhances growth of wild [23] and domestic birds [24]. Interestingly, the effects on growth and immuno- 
competence of probiotics, such as Lactobacilus sp., included in the diet of chickens is quite similar to those produced by antibiotics $[25,26]$, suggesting that both treatments eliminate detrimental bacterial strains and/or enhance proliferation of mutualistic strains with antibiotic production capacity. Therefore, it is possible that through bacterial interference, antibiotic producing bacteria are, at least partially, responsible for maintaining optimal intestinal flora and preventing colonization by exogenous pathogens [4, 27, 28].

Indigenous intestinal bacteria [4] vary depending on environmental factors, such as diet or habitat, as well as on properties of the digestive tract, including anatomy or $\mathrm{pH}$ [29]. Many factors affecting intestinal microbiota, however, are species-specific traits and therefore a genetic component determining the composition of the bacterial community found in the intestine of birds is also likely. Evidence of a host-genetic effect determining intestinal bacterial community (estimated through characterization of cloacal bacterial assemblages) has been recently obtained from a crossfostering experiment with nestlings of great spotted cuckoos and those of their magpie hosts [30]. Nestlings of those species were fed within the same nest by the same parents and, thus, the environmental components driving the establishment of a particular bacterial community within the intestine were partially controlled. We found significant differences in bacterial assemblages of the parasitic and host nestlings, although none of the phylotypes were specific in either great spotted cuckoos or magpies, which suggest a genetic (i.e., specific) component of the intestinal microbiota [30]. The environmental component of intestinal bacterial community in wild birds has also been demonstrated by means of interspecific cross-fostering experiments of nestlings [30, 31] and by comparing the cloacal microbial community of adults from different locations [32]. As we mentioned above, most of the environmental variation is likely mediated by among nests differences in nestling diets and feeding efforts by parents (i.e., parental effects), which might also have a genetic component in parents (i.e. indirect genetic effects [33]). Consequently, if the particularities of intestinal flora composition of nestlings are the consequence of indirect genetic effects of parental behaviour and are related to the probability of nestling recruitment, natural selection could act on such parental traits favouring those resulting in optimal intestinal flora of nestlings [33].

Although the study of the intestinal bacterial community of wild bird species has only recently attracted the attention of ornithologists, evidence of the prime role of these bacteria in determining nestling growth and probability of survival are accumulating. Apart from the unequivocal negative effects of pathogenic bacteria such as Escherichia coli, Salmonella spp. or Shigella spp. [34, 35], some beneficial effects have been detected in relation to the abundance of other microorganisms such as Lactobacillus sp. [34] or Enterococcus sp. [36]. Moreover, a relationship between gastrointestinal bacterial diversity and immunocompentence or body condition of hosts has also been detected in wild nestling birds [37]. Because the presence of beneficial bacteria in the gastrointestinal tract is correlated with the diversity of the bacterial community, the detected associations between phenotypic quality of nestlings and bacterial diversity were interpreted as resulting from the effect of beneficial bacteria [37].
The physiological benefits obtained by hosts from symbiotic intestinal bacteria are mainly explained by direct effects on food digestion allowing the degradation of some hardly digestible molecules and the synthesis of essential nutrients, but antimicrobial chemicals produced by some beneficial bacteria could also contribute to explain the detected relationship between microflora and fitness related traits. In natural conditions, however, it is not possible to isolate the importance of antibiotics produced by bacteria living in the gastrointestinal tract from other bacterial effects.

\section{Adaptive Transmission of Beneficial Bacteria}

Given the importance of beneficial bacteria in the host gastrointestinal tract, mechanisms allowing their transmission among individuals would be of selective advantage. Birds, when feeding their nestlings may transfer beneficial bacteria present in the saliva. One extreme example of the importance of such mouth-to-mouth transmission was provided by Kyle and Kyle [38] who reported that $100 \%$ of chimney swift (Chaetura pelagica) nestlings of less than $6 \mathrm{~d}$ old died during rehabilitation if the provided food did not contain saliva from healthy adult swifts. In contrast, nearly $100 \%$ of nestlings handfed with food inoculated with saliva were rehabilitated and released [38]. Since potentially pathogenic but also benign microorganisms were found within the oral cavities of adult and young swifts the authors suggested a potential role of microbial flora in saliva transfer.

The potential benefits associated to the transmission of beneficial bacteria have even been proposed as the reason explaining the high frequency of copulations of some bird species [39]. Beneficial sexually transmitted microbes would either protect females against future encounters with pathogens and/or serve as therapy against present infections [39]. Predictions from this hypothesis however cannot be easily tested and, apart from some pieces of information that matched with the hypothesis [39], including the experimental demonstration that gut bacteria can be transmitted sexually with a higher transmission rate when males are the infected sex [40], this hypothesis has not received further support. However, sexually transmitted diseases are likely common in birds [41, 42], and acquisition of barriers against them from antibiotic-producing bacteria would be of selective advantage both for bird males and females. A possible experimental test of the "beneficial sexually transmitted microbe hypothesis of avian copulations" would consist on the experimental infection of birds with pathogenic micro-organisms after having been subjected to experimental treatments of high vs. low rates of copulations. If the probability of acquiring beneficial bacteria increases with the number of copulations and the level of polygamy, individuals copulating several times with several healthy individuals should demonstrate a lower infection rate than individuals not allowed to perform effective copulations (i.e. cloacal contact). The experiment proposed, however, should control for the activation of immunity in the female reproductive tract due to copulations alone. If immune activity increases with the number of copulations, then pathogen invasion of the female cloaca may be less successful in multiply-copulating indi- 
viduals for that reason, not because of competition between microbes.

The acquisition of protective endosymbionts from conspecifics has recently been suggested as an important but underappreciated benefit of animals living in groups [43]. Lombardo [43] predicted that complex forms of sociality would have more likely evolved in host species that have to repeatedly obtain endosymbionts from conspecifics than in those who can obtain beneficial bacteria either directly from the environment, by vertical transmission, or only once in their lifetime. The communal roosting and the very frequent allopreening behaviours of wood hoopoes (Phoeniculidae) $[44,45]$ could be an example of the importance of social behaviour for maintaining mutualistic symbiotic bacteria. Similarly to the European hoopoes, Phoeniculidae species possess very special brown and malodorous preen secretions that occur in association with symbiotic bacteria [46, 47] (see below). Interestingly, in the Phoeniculidae species where the secretion has been studied (e.g. the green woodhoopoes, Phoeniculus purpureus), the detected bacteria was described as a new species (Enterococcus phoeniculicola). The individual contacts in communal roosting, as well as the very frequent allopreening behaviour detected in this species [45], could explain both the evolution of specific symbionts and the social acquisition of beneficial bacterial strains in green hoopoes.

Although more work is necessary before we can reach firm conclusions, these scenarios suggest that antibiotic producing bacteria might have played a prime role in the evolution of avian life history traits.

\section{Bacteria and the Uropygial Gland of Birds}

Preen gland secretion is used by birds, among other purposes, to prevent pathogenic infections of feathers and skin $[48,49]$. This function is mediated by antimicrobial chemicals that are directly secreted by the gland cells $[48,50]$. Recently, however, bacteria living in the uropygial gland of two species of Upupiformes of two different families, the European hoopoe (Upupidae) and green woodhoopoe (Phoeniculidae), have been considered as partially responsible for the particularities (stinky odour and brown colour) of their uropygial secretions $[46,47]$. The chemical composition of the secretions of these two species has been studied and reports have identified a complex mix of volatile compounds usually not present in the secretions of other species [51, 52]. Interestingly, some of the volatile compounds detected in the secretion of both species, such as the indole, are known to be metabolites of bacteria [53] that are active against some other bacteria [54]. This suggests the possibility that the symbiotic bacteria found in preen glands directly synthesise such chemicals. Evidence supporting a role for antibiotic producing bacteria determining the antimicrobial activity of uropygial gland secretions is almost exclusively restricted to studies performed by our research group on European hoopoes. Below we describe those findings and discuss the possibility that other species of birds use similar strategies.

Evidence for Antimicrobial Properties of Uropygial Secretions Being Mediated by Antibiotic-Producing Bacteria
In contrast to woodhoopoes, European hoopoes only harbour bacteria in their uropygial gland during reproduction and exclusively in nestlings and nesting (i.e., incubating or brooding) females. Furthermore, only the brown and malodorous secretions harboured bacteria, allowing comparisons of antimicrobial activity of secretions with (brown) and without (white) bacteria from individuals of the same species and/or even sex [16]. Several pieces of information suggested that antibiotic producing bacteria were the responsible of the antimicrobial activity of brown secretion of hoopoes. The first one is that brown but not white secretions contained bacteria and showed antimicrobial activity against Bacillus licheniformis [16]. The second one is that most of the cultivable strains isolated from the uropygial secretions belonged to the genus Enterococcus, a genus that produces a well known group of bacteriocins with broad antimicrobial capabilities [i.e., enterocins, 55]. In accordance with the expected production of enterocins, one bacterial strain of Enterococcus faecalis, isolated from the uropygial gland secretion of a nestling hoopoe, produced at least two different bacteriocins with antimicrobial activity against a wide range of bacteria [56]. Furthermore, most of the bacterial colonies isolated from secretions of European hoopoes showed antimicrobial activity against the feather-degrading bacterium Bacillus licheniformis [16]. Importantly, the antimicrobial activity of those colonies was inhibited by the addition of protease suggesting that bacteriocins, and not other secreted chemicals, were responsible for the antimicrobial properties demonstrated by enterococci living in the uropygial gland of European hoopoes when grown in standard solid media [16].

Symbiotic bacteria may also be responsible for the occurrence of antimicrobial chemicals of non-peptidic nature in the uropygial gland secretions of hoopoes (see above). We have tested this hypothesis by experimental injections of a broad-spectrum antibiotic in the uropygial gland of nestling hoopoes during development [52]. The comparison of the chemical composition of uropygial secretions between experimental and control nestlings revealed that the former had lost volatile chemicals with antimicrobial properties. Furthermore, the comparison of the antimicrobial power of a mixture of volatile chemicals reflecting the concentrations found in secretions from experimental and control nestlings resulted in clear differences. The blend reflecting the natural composition of secretions (control birds) showed activity against all tested bacterial strains, while that of experimental nestlings was completely ineffective [52]. These results strongly suggest a role of symbiotic bacteria determining the antimicrobial properties of the dark uropygial gland secretion of hoopoes that is mediated, not only by antimicrobial peptides (i.e., bacteriocins), but also by several volatiles with antibiotic activity.

\section{Protection Against Feather Degrading Bacteria}

Hoopoes, as other birds, use the uropygial secretion to spread it on feathers. Given that secretion is full of symbiotic bacteria with antagonistic activity against other microorganisms (see above), part of the antimicrobial properties of secretion may be due to the symbionts. The effects of bacteriocins from the enterococci symbionts preventing feather degradation during the nesting phase of hoopoes would, in any case, be independent of those from other chemicals of nonpeptidic nature. In an experiment performed in laboratory 
conditions, we found support for the predicted benefits after testing for the independent effects of both bacteriocin and symbiotic bacteria in feather-degradation rate caused by the feather degrading Bacillus licheniformis. Briefly, the addition of either bacteriocin MR-10 (produced by enterococci isolated from hoopoe glands) or the producer Enterococcus strain MRr-10-3 [56] to feathers of European hoopoes in culture media containing the feather degrading bacteria $\mathrm{Ba}$ cillus licheniformis [see, 57] invariably resulted in a statistically significantly decrease of feather degradation [58]. Therefore, since Bacillus licheniformis is quite abundant in feathers of wild birds [57, 59], the detected effects of both Enterococcus strains and secretions on feather degradation by $B$. licheniformis in laboratory conditions suggest that in natural conditions the antibiotic producing bacteria living in the uropygial gland of hoopoes protect feathers of hoopoes from degradation.

Protection of feathers from degrading microorganisms is believed to be one of the main functions of the uropygial gland secretions of birds [48]. Bacteria have only been identified in the secretions of European hoopoes and woodhoopoes (see above) and, consequently, in most birds the protection of feathers is apparently mainly mediated by antimicrobial activity of secretion chemicals produced by birds themselves [50,60]. Uropygial oils might however promote growth of non-pathogenic bacteria that, due to their interference properties, would outcompete or otherwise exclude parasitic or pathogenic microbes. Pugh and Evans [61] detected that the presence of uropygial oil on feathers promotes growth of some fungi but impedes the establishment of others with queratinolitic activity, and that the effect of oils on growing fungi depend on the bird species. Recently, Shawkey et al. [48] suggested that the uropygial oil may also promote the growth of mutualistic microorganisms that exclude others with pathogenic effects. Shawkey et al. [48] isolated bacteria from feathers of house finches (Carpodactus mexicanus) and studied the effect of the bird uropygial secretion on them. Briefly, they estimated inhibition intensity of the uropygial secretion against all detected bacterial strains, as well as the queratinase production of each isolate. They found that the uropygial secretion inhibited growth of most of the queratinolitic strains, but not of those with no or very low queratinolitic activity (see Table 1 in [48]). Intriguingly, Enterococus faecalis was one of the bacteria detected in feathers of house finches for which the uropygial secretion did not demostrate antagonistic activity. This bacterium produced queratinase at a relatively low rate but, simililarly to most Enterococcus faecalis strains assayed, should produce enterocines and some other antimicrobial chemicals [55, 62] that, together with antimicrobial chemicals synthesised by birds, would prevent the establishment of others microorganisms with queratinolitic (i.e. feather degrading) activity $[48,59]$.

Given that the presence of bacteria strains with unknown pathogenic effects on bird feathers is likely to be common [48], a beneficial effect for birds of the establishment of such bacteria on the feathers surface, impeding colonization by pathogenic bacteria, is also likely. Birds, by spreading some chemicals on their feathers might not only protect them from degrading bacteria directly, but also indirectly. Components of the uropygial secretion could promote the establishment of other bacteria that are harmless to hosts but that impede the colonization of feathers by virulent bacteria. Predictions from this hypothesis have never been tested, but empirical and experimental tests are possible. For instance, a negative relationship between abundance estimates of feather degrading bacteria and bacteria diversity would be in accordance with the hypothesis. Furthermore, laboratory conditions favouring the establishment on feathers of non-degrading bacteria should prevent feather degradation by other bacteria with queratinolitic activity.

\section{Protection Against Egg Infection}

European hoopoes also spread the uropygial gland secretion on eggshells. In fact, it has been suggested that the change in egg colouration along the incubation period from pale blue to brown colour is due to the impregnation of eggshells with uropygial secretion of hoopoe females [47]. Thus, we predicted that hatching success of hoopoes may benefit from bacteriocins produced by symbiotic enterococci [16]. We attempted to demonstrate such benefit by deactivation of bacteriocins in nests of hoopoes by mean of the periodical addition of protease along the incubation period. Results were in accordance with the expected experimental effect; i.e., hatching failures were more common in experimental than in control nests. Additionally, the effect of protease was not found in the spotless starling (Sturnus unicolor), a species that apparently do not harbour bacteria in the uropygial gland, further suggesting a link between the effect of protease and bacteria producing antimicrobial peptides [16]. Therefore, these results suggest a role of antibiotic producing bacteria preventing trans-shell infection of hoopoe embryos.

The selective pressures exerted by pathogenic bacteria on avian embryos are supposed to be intense given that around $10 \%$ of the avian eggs fail to hatch in natural conditions [63, 64], and avian eggs present defence mechanisms that protect embryos from bacterial infection. These mechanisms are mainly known from studies of poultry and are constituted by, first, a physical barrier represented by the shell and membranes that envelop the embryo, and second, a chemical barrier represented by some of the proteins dissolved in the albumen. These last components include lysozymes, ovotransferrins, ovomucoids, etc. and are therefore transmitted by the female [65-67]. Some other adaptations proposed to diminish the probability of trans-shell embryo infection are protective behaviours, such as the use of green plants with antimicrobial properties $[68,69]$, or the increase of the incubation effort [70], given that incubation reduces bacterial growth and diversity on the eggshell [71, 72]. While the hypothesised antimicrobial activity of green plants would likely be mediated by volatile compounds with directly antimicrobial properties, mechanisms underling the experimentally detected effects of incubation on growth, density, and diversity of bacterial community at the eggshell [71] are not so clear.

The environment of incubated eggs, with higher temperature and lower humidity than that of non-incubated eggs, might directly prevent pathogen invasion $[71,73]$. Moreover, the incubating environment could also amplify the possible effects of antimicrobial volatile chemicals from plants used in nest building, explaining the detected low bacterial load on incubated eggs. Female parents may also use feathers or the epidermal layer of their brood patches, previously 
daubed with preen gland secretion, to inoculate shells with antibiotic agents or with certain protective microbial species [71]. Another possible reason explaining the effect of incubation preventing the contagion of avian embryos by pathogenic bacteria could be related to the existence of nonpathogenic bacteria on the egg surface, or in the female's breast feathers in contact with the egg surface, that could interfere with pathogenic bacteria, thereby preventing embryo infection. Although this possibility has been recently suggested by Cook et al. [71] and Baggott and Graeme-Cook [66], evidence of the importance of bacterial interference as a barrier preventing embryo infection was actually found several decades ago, not on the eggshell but on the allantoid membrane of chicken eggs. More than forty years ago laboratory experiments with embryonated eggs demonstrated that prior allantoic infection with avirulent staphylococci afforded significant protection against subsequent challenge with virulent strains, not only staphylococci, but also others such as Salmonella typhimurium, Escherichia coli, or even against one strain of influenza virus [74, 75]. A generalization of bacterial interference processes diminishing the probability of embryo infection is possible because of the existence of beneficial bacteria in the digestive tract and other bird organs such as the uropygial gland (see above). Preening behaviour would facilitate the contact of the incubating bird with its eggs inducing the transmission of these symbiotic/commensal bacteria to the eggshell and to the allantoid, which would prevent its contagion by pathogenic bacteria [see, 76]. This possibility could be facilitated if eggshells become in contact with oil from the uropygial secretion that, as has been suggested for feathers could promote growth of beneficial bacteria.

After the pioneering studies mentioned above, this research line was however abandoned until now, probably due to methodological problems inherent to the study of microbiota in natural conditions. This is a promising line of research that, because of the antimicrobial chemical composition of most uropygial secretions studied, offers the possibility to study coevolution between preen secreted chemicals and bacteria, which are not killed but promoted because of their interference properties against pathogenic bacteria. This hypothesis can be tested by, for instance, exploring interspecific variations in both chemical and bacterial diversity of uropygial glands and eggshell of wild birds. The bacterial communities on the eggshell of bird species using antibiotic producing bacteria should be more dense but less diverse than those of the eggshell of other species. Specific bacteria that appear at high density on the eggshell of a target species of bird (as in hoopoes) would be a good candidate as beneficial-antimicrobial-producing bacteria. Detection of antimicrobial activity of such bacteria against pathogenic microorganisms, either alone or together with preen secretions, would also be necessary to demonstrate potential beneficial effects for bird hosts.

\section{Bacteria from Allochthonous Biological Materials}

Another possibility for the existence of relationships between birds and bacteria is the use of material likely containing beneficial microorganims, including those producing antibiotic substances. Bacteria are ubiquitous microorgan- isms that are in symbiosis with most (if not all) macroorganisms, including plants and animals. Bacterial communities are usually host specific and, even within the same hosts, vary depending on the organ, structure, or body location sampled. Consequently, when birds collect or consume particular biological products they are also collecting particular microbiota. Since flora associated to some biological materials could have beneficial effects on collecting birds, benefits associated to the collection of allochthonous biological materials could be related to antibiotic substances produced by bacteria inhabiting the collected materials. Thus, bacterial communities could play an important role when birds select materials for food, nest building, etc. We briefly expose below the possibility that antimicrobial properties of bacterial communities found on feathers collected for nest building may affect the selection of nest lining materials.

Many different species of birds use feathers in their nests, and, as we mentioned above, feathers sometimes harbour a complex bacterial community that mostly include feather degrading bacteria [48, 59]. Most of these bacteria, as those of the genera Enterococcus, Staphylococcus [77] and Streptomices [78], are known producers of antibiotic substances and, therefore, if present in transported-to-the-nest feathers they could play a role preventing the establishment of other bacteria within the nest environment. For instance, Bacillus licheniformis is perhaps the most common feather degrading bacteria species in feathers of wild birds (Burtt and Ichida 1999) and, apart from its pathogenic activity on avian feathers, it is also known to produce antimicrobial substances [7981], that are active not only against different strains belonging to the genera Bacillus, Corynebacterium, Enterococcus, and Micobacterium, but also against amoebas [82] and fungi $[83,84]$. Consequently, the use of feathers by many species of birds for nest lining could in fact be a growing culture of B. licheniformis and some other bacteria that prevent the establishment of pathogenic bacteria in the nest environment. Alternatively, the use of feathers containing feather degrading bacteria could also be costly for adults and nestlings if the use of feathers increases the risk of infection by the transported bacteria. The relationship between birds and feather degrading bacteria has always been suggested to be parasitic but, under this hypothesis, a positive association is also possible. Birds, through preening behaviour, may control and/or prevent growth of feather degrading bacteria on their own plumage, but those bacteria growing on the unprotected allochthonous nest material might, thanks to their antibiotic production, protect eggs and nestlings from other pathogens.

\section{FINAL REMARKS}

We have here reviewed the few available results suggesting that birds are associated with antibiotic producing bacteria, and that this association results in fitness advantages for hosts. The evidence accumulated up-to-date does not lend itself to an easy generalization of the importance of such kind of associations, and a large research effort is still needed to test predictions of the hypothetical relationships in different contexts. We have exposed theoretical arguments suggesting that the existence of beneficial symbiotic bacteria should commonly occur within host birds, and that hosts can 
use these bacteria to prevent pathogenic infections. Furthermore, we suggest that birds might also promote growth of beneficial bacteria by using specific chemicals or allochthonous material. We hope that these points may encourage ecologists to further investigate the possible role of antibiotic producing bacteria in bird life history traits evolution.

\section{ACKNOWLEDGEMENTS}

We received financial support from the Ministerio de Educación y Ciencia/FEDER (projects CGL200506975/BOSFEDER and CGL2007-61251/BOS) and the Junta de Andalucía (projects P06-RNM-02177 and RNM 345). We are indebted to Carmen Zamora, Aldo Poiani and one anonymous referee for their comments on a previous version of the manuscript.

\section{REFERENCES}

[1] Moran NA. Symbiosis. Curr Biol 2006; 16: R866-R71.

[2] Ji G, Beavis R, Novick RP. Bacterial interference caused by autoinducing peptide variants. Science 1997; 276: 2027-30.

[3] Riley MA, Wertz JE. Bacteriocines: evolution, ecology, and application. Ann Rev Microbiol 2002; 56: 117-37.

[4] Berg RD. The indigenous gastrointestinal microflora. Trends Microbiol 1996; 4: 430-5.

[5] Dillon RJ, Dillon VM. The gut bacteria of insects: nonpathogenic interactions. Ann Rev Entomol 2004; 49: 71-92.

[6] Kellner RLL, Dettner K. Differential efficacy of toxic pederin in deterring potential arthropod predators of Paederus (Coleoptera: Staphylinidae) offspring. Oecologia 1996; 107: 293-300.

[7] Lindquist N, Barber PH, Weisz JB. Episymbiotic microbes as food and defence for marine isopods: unique symbioses in a hostile environment. Proc R Soc Lond B 2005; 272: 1209-16.

[8] Jones EO, White A, Boots M. Interference and the persistence of vertically transmitted parasites. J Theor Biol 2007; 246: 10-17.

[9] Klaenhammer TR. Bacteriocins of lactic-acid bacteria. Biochimie 1988; 70: 337-49.

[10] Frank SA. Models of parasite virulence. Q Rev Biol 1996; 71: $37-$ 78

[11] Haine ER. Symbiont-mediated protection. Proc R Soc Lond B 2008; 275: 353-61.

[12] Kikuchi Y, Hosokawa T, Fukatsu T. Insect-microbe mutualism without vertical transmission: a stinkbug acquires a beneficial gut symbiont from the environment every generation. Appl Environ Microbiol 2007; 73: 4308-16.

[13] Gil-Turnes MS, Hay ME, Fenical W. Symbiotic marine-bacteria chemically defend crustacean embryos from a pathogenic fungus. Science 1989; 246: 116-8.

[14] Gil-Turnes MS, Fenical W. Embryos of Homarus americanus are protected by epibiotic bacteria. Biol Bull 1992; 182: 105-8.

[15] Banning J, Weddle A, Wahl III G, et al. Antifungal skin bacteria, embryonic survival, and communal nesting in four-toed salamanders, Hemidactylium scutatum. Oecologia 2008; 156: 4239.

[16] Soler JJ, Martin-Vivaldi M, Ruiz-Rodriguez M, et al. Symbiotic association between hoopoes and antibiotic-producing bacteria that live in their uropygial gland. Funct Ecol 2008; 22: 864-71.

[17] Barton ES, White DW, Cathelyn JS, et al. Herpesvirus latency confers symbiotic protection from bacterial infection. Nature 2007; 447: 326-7.

[18] Tagg JR, Dierksen KP. Bacterial replacement therapy: adapting 'germ warfare' to infection prevention. Trends Biotechnol 2003; 21: 217-23.

[19] Currie CR, Scott JA, Summerbell RC, Malloch D. Fungus-growing ants use antibiotic-producing bacteria to control garden parasites. Nature 1999; 398: 701-4.

[20] Stow A, Beattie A. Chemical and genetic defenses against disease in insect societies. Brain Behav Immun 2008; 22: 1009-13.

[21] Stamand L, Lavoie MC. Antibiotic-resistance and production of inhibitory substances among bacterial strains isolated from the oral cavities of balb/c mice. J Dent Res 1988; 67: 1518-22.
[22] Kelly D, Conway S, Aminov R. Commensal gut bacteria: mechanisms of immune modulation. Trends Immunol 2005; 26 : 326-33.

[23] Potti J, Moreno J, Yorio P, et al. Bacteria divert resources from growth for magellanic penguin chicks. Ecol Lett 2002; 5: 709-14.

[24] Dibner JJ, Richards JD. Antibiotic growth promoters in agriculture: history and mode of action. Poultry Sci 2005; 84: 634-43.

[25] Apata DF. Growth performance, nutrient digestibility and immune response of broiler chicks fed diets supplemented with a culture of lactobacillus bulgaricus. J Sci Food Agric 2008; 88: 1253-8.

[26] Thongsong B, Kalandakanond-Thongsong S, Chavananikul V Effects of the addition of probiotic containing both bacteria and yeast or an antibiotic on performance parameters, mortality rate and antibiotic residue in broilers. Thai J Vet Med 2008; 38: 17-26.

[27] Jin LZ, Ho YW, Abdullah N, Jalaludin S. Probiotics in poultry: modes of action. World's Poult Sci J 1997; 53: 351-68.

[28] Patterson JA, Burkholder KM. Application of prebiotics and probiotics in poultry production. Poultry Sci 2003; 82: 627-31.

[29] Stevens CE, Hume ID. Contributions of microbes in vertebrate gastrointestinal tract to production and conservation of nutrients. Physiol Rev 1998; 78: 393-427.

[30] Ruiz-Rodriguez M, Lucas FS, Heeb P, Soler JJ. Differences in intestinal microbiota between avian brood parasites and their hosts. Biol J Lin Soc 2009; 96: 406-14.

[31] Lucas FS, Heeb P. Environmental factors shape cloacal bacterial assemblages in great tit Parus major and blue tit P. caeruleus nestlings. J Avian Biol 2005; 36: 510-16.

[32] Klomp JE, Murphy MT, Smith SB, Mckay JE, Ferrera I, Reysenbach AL. Cloacal microbial communities of female spotted towhees Pipilo maculatus: microgeographic variation and individual sources of variability. J Avian Biol 2008; 39: 530-8.

[33] Mousseau TA, Fox CW. The adaptive significance of maternal effects. Trends Ecol Evol 1998; 13: 403-7.

[34] Lombardo MP, Thorpe PA, Cichewicz R, et al. Communities of cloacal bacteria in Tree Swallow families. Condor 1996; 98: 16772.

[35] Mills TK, Lombardo MP, Thorpe PA. Microbial colonization of the cloacae of nestling tree swallows. Auk 1999; 116: 947-56.

[36] Moreno J, Briones V, Merino S, Ballesteros C, Sanz JJ, Tomás G. Beneficial effects of cloacal bacteria on growth and fledging size in nestling pied flycatchers (Ficedula hypoleuca) in Spain. Auk 2003; 120: 784-90.

[37] Ruiz-Rodriguez M, Soler JJ, Lucas F, et al. Bacterial diversity at the cloaca relates to an immune response in magpie Pica pica and to body condition of great spotted cuckoo Clamator glandarius nestlings. J Avian Biol 2009; 40: 42-8.

[38] Kyle PD, Kyle GZ. An evaluation of the role of microbial flora in the salivary transfer technique for hand-rearing chimney swifts. Wild Rehabil 1993; 8: 65-71.

[39] Lombardo MP, Thorpe PA, Power HW. The beneficial sexually transmitted microbe hypothesis of avian copulation. Behav Ecol 1999; 10: 333-50.

[40] Kulkarni S, Heeb P. Social and sexual behaviours aid transmission of bacteria in birds. Behav Process 2007; 74: 88-92.

[41] Sheldon BC. Sexually-transmitted disease in birds - occurrence and evolutionary significance. Phil Trans R Soc Lond B 1993; 339: 491-7.

[42] Poiani A. Do cloacal pathogenic microbes behave as sexually transmitted parasites in birds? Open Ornithol J 2010; 3: 65-78.

[43] Lombardo M. Access to mutualistic endosymbiotic microbes: an underappreciated benefit of group living. Behav Ecol Sociobiol 2008; 62: 479-97.

[44] del Hoyo J, Elliot A, Sargatal J. Handbook of the birds of the world. mousebirds to hornbills. mousebirds, trogons, kingfishers, todies, motmots, bee-eaters, rollers, ground-rollers, cuckoo-rollers, hoopoes, wood-hoopoes, hornbills. Barcelona: Lynx Editions 2001

[45] Radford AN, Du Plessis MA. Dual function of allopreening in the cooperatively breeding green woodhoopoe, phoeniculus purpureus. Behav Ecol Sociobiol 2006; 61: 221-30.

[46] Law-Brown J, Meyers PR. Enterococcus phoeniculicola sp. nov., a novel member of the enterococci isolated from the uropygial gland of the red-billed woodhoopoe, Phoeniculus purpureus. Int J Syst Evol Microbiol 2003; 53: 683-5.

[47] Martin-Vivaldi M, Ruiz-Rodriguez M, Soler JJ, et al. Seasonal, sexual and developmental differences in hoopoe upupa epops preen 
gland morphology and secretions: evidence for a role of bacteria. $\mathrm{J}$ Avian Biol 2009; 40: 191-205.

[48] Shawkey MD, Pillai SR, Hill GE. Chemical warfare? Effects of uropygial oil on feather-degrading bacteria. J Avian Biol 2003; 34: 345-9.

[49] Bandyopadhyay A, Bahttacharyya SP. Influence of fowl uropygial gland and its secrretory lipid components on growth of skin surface bacteria of fowl. Indian J Exp Biol 1996; 37: 1218-22.

[50] Jacob J, Ziswiler V. The uropygial gland. In: Farner DS, King JR, Parker KC, Eds. Avian Biology. London: Academic Press 1982; pp. 359-62.

[51] Burger BV, Reiter B, Borzyk O, Du Plessis MA. Avian exocrine secretions. I. chemical characterization of the volatile fraction of the uropygial secretion of the green woodhoopoe, Phoeniculus purpureus. J Chem Ecol 2004; 30: 1603-11.

[52] Martín-Vivaldi M, Peña A, Peralta-Sánchez JM, et al. Antimicrobial chemicals in hoopoe preen secretions are produced by symbiotic bacteria.Proc R Soc Lond B 2009; doi: 10.1098/8spb. 2009. 1377.

[53] Tavaria FK, Dahl S, Carballo FJ, Malcata FX. Amino acid catabolism and generation of volatiles by lactic acid bacteria. $\mathrm{J}$ Dairy Sci 2002; 85: 2462-70.

[54] Ozturk A, Abdullah MI. Toxicological effect of indole and its azo dye derivatives on some microorganisms under aerobic conditions. Sci Total Environ 2006; 358: 137-42.

[55] Franz CMAP, van Belkum MJ, Holzapfel WH, Abriouel H, Galvez A. Diversity of enterococcal bacteriocins and their grouping in a new classification scheme. FEMS Microbiol Rev 2007; 31: 293310 .

[56] Martín-Platero AM, Valdivia E, Ruíz-Rodríguez $\mathrm{M}$, et al. Characterization of antimicrobial substances produced by Enterococcus faecalis MRR 10-3, isolated from the uropygial gland of the hoopoe Upupa epops. Appl Environ Microbiol 2006; 72: 4245-9.

[57] Burtt EHJ, Ichida JM. Occurrence of feather-degrading bacilli in the plumage of birds. Auk 1999; 116: 364-72.

[58] Ruiz-Rodríguez M, Valdivia E, Soler JJ, Martín-Vivaldi M, Martín-Platero AM, Martínez-Bueno M. Symbiotic bacteria living in the hoopoe's uropygial gland prevent feather degradation. J Exp Biol 2009; 212: 3621-6.

[59] Gunderson AR. Feather degrading bacteria: a new frontier in avian and host-parasite research? Auk 2008; 125: 972-79.

[60] Jacob J, Eigener U, Hoppe U. The structure of preen gland waxes from pelecaniform birds containing 3,7-dimethyloctan-1-ol - an active ingredient against dermatophytes. Z Naturforsch Sect C-A J Biosci 1997; 52: 114-23.

[61] Pugh GJF, Evans MD. Keratinophilic fungi associated with birds .2. physiological studies. Trans Br Mycol Soc 1970; 54: 241-50.

[62] Giraffa G. Functionality of enterococci in dairy products. Int J Food Microbiol 2003; 88: 215-22.

[63] Koenig WD. Ecological and social factors affecting hatchability of eggs. Auk 1982; 99: 526-36.

[64] Spottiswoode C, Møller AP. Genetic similarity and hatching success in birds. Proc R Soc Lond B 2004; 271: 267-72.

[65] Board RG, Clay C, Lock J, Dolman J. The egg: a compartmentalized, aseptically packaged food. In: Board RG, Fuller R, Eds. Microbiology of the avian egg. London: Chapman \& Hall 1994; pp. 43-62.

[66] Baggott GK, Graeme-Cook K. Microbiology of natural incubation. In: Deeming DC, Ed. avian incubation behaviour, environment and evolution. Oxford: Oxford University Press 2002; pp.179-91
[67] Shawkey MD, Kosciuch KL, Liu M, et al. Do birds differentially distribute antimicrobial proteins within clutches of eggs? Behav Ecol 2008; 19: 920-27.

[68] Clark L, Mason JR. Use of nest material as insecticidal and antipathogenic agents by the european starling. Oecologia 1985; 67: 169-76.

[69] Clark L, Mason JR. Effect of biologically active plants used as nest material and the derived benefit to starling nestlings. Oecologia 1988; 77: 174-80.

[70] Cook MI, Beissinger SR, Toranzos GA, Rodriguez RA, Arendt WJ Trans-shell infection by pathogenic micro-organisms reduces the shelf life of non-incubated bird's eggs: a constraint on the onset of incubation? Proc R Soc Lond B 2003; 270: 2233-40.

[71] Cook MI, Beissinger SR, Toranzos GA, Arendt WJ. Incubation reduces microbial growth on eggshells and the opportunity for trans-shell infection. Ecol Lett 2005; 8: 532-7.

[72] Shawkey MD, Firestone MK, Brodie EL, Beissinger SR. Avian incubation inhibits growth and diversification of bacterial assemblages on eggs. PLoS ONE 2009; 4: e4522.

[73] Beissinger SR, Cook MI, Arendt WJ. The shelf life of bird eggs: testing egg viability using a tropical climate gradient. Ecology 2005; 86: 2164-75.

[74] McCabe WR, Digenio T. Bacterial interference induced in embryonated eggs by staphylococci. J Clin Invest 1967; 46: 45362.

[75] Ribble JC, Shinefield HR. Bacterial interference in chick embryos. J Clin Invest 1967; 46: 446-52.

[76] Brook I. Bacterial interference. Crit Rev Microbiol 1999; 25: 15572.

[77] Parisien A, Allain B, Zhang J, Mandeville R, Lan CQ. Novel alternatives to antibiotics: bacteriophages, bacterial cell wall hydrolases, and antimicrobial peptides. J Appl Microbiol 2008; 104: 1-13.

[78] Omura S, Ikeda H, Ishikawa J, et al. Genome sequence of an industrial microorganism streptomyces avermitilis: deducing the ability of producing secondary metabolites. Proc Natl Acad Sci USA 2001; 98: 12215-20.

[79] Callow RK, Work TS. Antibiotic peptides from bacilluslicheniformis - licheniformins A, B and C. Biochem J 1952; 51: 558-67.

[80] Haavik HI. Studies on formation of bacitracin by bacilluslicheniformis - effect of glucose. J Gen Microbiol 1974; 81: 38390 .

[81] Simlot MM, Specht D, Pfaender P. Antibiotics producing enzymes of Bacillus Licheniformis. Hoppe-Seylers Zeitschrift fur Physiol Chem 1972; 353: 759

[82] Galvez A, Maqueda M, Cordovilla P, Martinezbueno M, Lebbadi M, Valdivia E. Characterization and biological activity against Naegleria fowleri of amoebicins produced by Bacillus licheniformis D-13. Antimicrob Agents Chemother 1994; 38: 131419

[83] Lebbadi M, Galvez A, Maqueda M, Martinez Bueno M, Valdivia E. Fungicin M4 - A narrow spectrum peptide antibiotic from Bacillus licheniformis M-4. J Appl Bacteriol 1994; 77: 49-53.

[84] Patel VJ, Tendulkar SR, Chattoo BB. Bioprocess development for the production of an antifungal molecule by Bacillus licheniformis BC98. J Biosci Bioeng 2004; 98: 231-5.

This is an open access article licensed under the terms of the Creative Commons Attribution Non-Commercial License (http://creativecommons.org/licenses/_by-nc/3.0/) which permits unrestricted, non-commercial use, distribution and reproduction in any medium, provided the work is properly cited. 